\title{
Novel solid polymer electrolytes based on poly(trimethylene carbonate) and lithium hexafluoroantimonate
}

\author{
Maria Manuela Silva*, Paula Barbosa, Alan Evans, Michael John Smith \\ Departamento de Química, Universidade do Minho, Gualtar, 4710-057 Braga, Portugal \\ Received 2 March 2006; received in revised form 4 April 2006; accepted 12 May 2006 \\ Available online 8 August 2006
}

\begin{abstract}
The results of the characterization of a polymer electrolyte system based on the poly(trimethylene carbonate) host matrix, with lithium hexafluoroantimonate as guest salt, are described in this study. Electrolytes with lithium salt compositions with values of $n$ between 5 and 100 (where $n$ represents the total number of monomeric cation-coordinating units $-\left(\mathrm{O}=\mathrm{COCH}_{2} \mathrm{CH}_{2} \mathrm{CH}_{2} \mathrm{O}\right)$ - per lithium ion) were prepared by co-dissolution and deposition from acetonitrile. The solvent-casting technique was used to prepare flexible, transparent and self-supporting films of electrolytes which were characterized by measurements of conductivity, cyclic voltammetry, differential scanning calorimetry and thermogravimetry.

(c) 2006 Elsevier Masson SAS. All rights reserved.
\end{abstract}

Keywords: Polymer electrolytes; Lithium hexafluoroantimonate; Conductivity; Thermal stability

\section{Introduction}

Since the publication of the earliest studies of solid polymer electrolytes (SPEs) in 1973 [1], this domain has benefited from the attention of researchers with diverse scientific backgrounds. A remarkable variety of development strategies have been applied to produce electrolytes with appropriate chemical, electrochemical, thermal and mechanical properties for applications in sensors, displays or advanced batteries [2-8].

While first-generation SPEs were based on commercial poly(ethylene oxide) (abbreviated as PEO) or PEO-derived host matrices, subsequent studies were aimed at the improvement of polymer hosts, the development of salts with improved characteristics and the use of conductivity-enhancing additives. The universal acceptance of evidence that ionic conductivity increases with the amorphous content of the host polymer [9] renewed interest in developing novel matrices. The exploration of block co-polymer hosts [10], sol-gel derived hybrid materials [11] and inter-penetrating [12] or inter-connecting [13] polymer blends and the use of nano-dimensioned inorganic fillers [14] were motivated by the search for improved host char-

\footnotetext{
* Corresponding author. Tel.: +351 253 604100; fax: +351 253678983 .

E-mail address: nini@quimica.uminho.pt (M. Manuela Silva).
}

acteristics. The commercially-driven nature of this research, restrictions arising from the need to produce stable interfaces, to pass stringent safety tests and to limit production costs, led to the proposal of plasticized matrices [15-19].

In this paper a novel polymer-salt combination has been characterized. The polymer component has already demonstrated the capacity to provide good thermal, mechanical and electrochemical stability [20-23]. The solubilization of lithium hexafluoroantimonate in the polycarbonate host has been shown to provide access to electrolyte compositions with encouraging electrochemical and physical characteristics.

\section{Experimental}

\subsection{Materials}

High molar mass $\mathrm{p}$ (TMC) $\left(3 \times 10^{5} \mathrm{~g} \mathrm{~mol}^{-1}\right.$, Shell Chemicals, Houston, TX, USA) was dried by argon/vacuum purge cycles at $70{ }^{\circ} \mathrm{C}$ for 7 days. Lithium hexafluoroantimonate (Alfa Aesar, 99\%) was used without further purification. Acetonitrile (Aldrich, anhydrous 99.9\%) was dried over molecular sieves prior to use. Electrolyte samples were prepared and manipulated within high-integrity dry argon-filled gloveboxes. 


\subsection{Sample preparation}

Homogeneous solutions of $\mathrm{p}(\mathrm{TMC})$ and lithium hexafluoroantimonate were prepared by stirring known masses of polymer and lithium salt in acetonitrile under a dry argon atmosphere. The resulting solutions were decanted into glass rings and the solvent was removed slowly by evaporation to form films of approximately $150 \mu \mathrm{m}$ thickness. Residual solvent was removed by drying at $60^{\circ} \mathrm{C}$. In accordance with current practice, an SPE formulation with $15-\left(\mathrm{O}=\mathrm{COCH}_{2} \mathrm{CH}_{2}\right.$ $\mathrm{CH}_{2} \mathrm{O}$ )- monomer units per lithium ion was identified as $(\mathrm{TMC})_{15} \mathrm{LiSbF}_{6}$.

\subsection{Measurements}

Total ionic conductivities of electrolyte samples were determined using a constant-volume support [24] with gold ionblocking electrodes located within a Buchi TO 50 oven. The sample temperature was evaluated by a type $\mathrm{K}$ thermocouple positioned close to the electrolyte film and impedance measurements were carried out (Solartron 1250 FRA, 1286 ECI) between 20 and $90^{\circ} \mathrm{C}$. Repeated measurements on samples confirmed that reproducibility was better than $5 \%$.

Samples were subjected to thermal analysis in $40 \mu \mathrm{L}$ aluminium cans with perforated lids under a flowing argon atmosphere and between -40 and $350^{\circ} \mathrm{C}$ at a heating rate of $5^{\circ} \mathrm{C} \mathrm{min}^{-1}$ (Mettler DSC 821e). Thermogravimetric studies were also conducted under an argon atmosphere (Rheometric Scientific TG 1000) at a heating rate of $10^{\circ} \mathrm{C} \mathrm{min}^{-1}$.

Evaluation of the electrochemical stability was carried out under an argon atmosphere using a two-electrode cell configuration. A $25 \mu \mathrm{m}$ diameter gold microelectrode was used after polishing, washing with THF and drying with a hot-air blower. The measuring cell was assembled by centering a sample of electrolyte on a clean lithium disk (Aldrich, 99.9\%, $10 \mathrm{~mm}$ diameter, $1 \mathrm{~mm}$ thick), placing a small volume $(0.20 \mu \mathrm{L})$ of THF on the microelectrode surface and using a clamp to maintain the microelectrode in secure contact with the electrolyte. Measurements were conducted at a scan rate of $10 \mathrm{mV} \mathrm{s}^{-1}(\mathrm{Au}-$ tolab PGSTAT-12 (Eco Chemie)), at room temperature, within a Faraday cage located inside the measurement glovebox.

\section{Results and discussion}

\subsection{Thermal behavior of electrolytes}

One of the most restrictive aspects of commercial PEO and PEO-derived host networks is related to the tendency of this host matrix to form crystalline complexes with guest salts or to phase separate and form spherulites. In contrast, the undoped $\mathrm{p}$ (TMC) matrix is a completely amorphous material with a glass transition temperature $(\mathrm{Tg})$ of $-18^{\circ} \mathrm{C}$ and a thermal stability limit (Td) of about $200^{\circ} \mathrm{C}$. All the previously characterized $\mathrm{p}$ (TMC)-based electrolyte systems were found to be completely amorphous over a wide range of salt compositions. The mechanical properties of these systems are however clearly influenced by the choice of guest salt. In the $(\mathrm{TMC})_{n} \mathrm{LiSbF}_{6}$

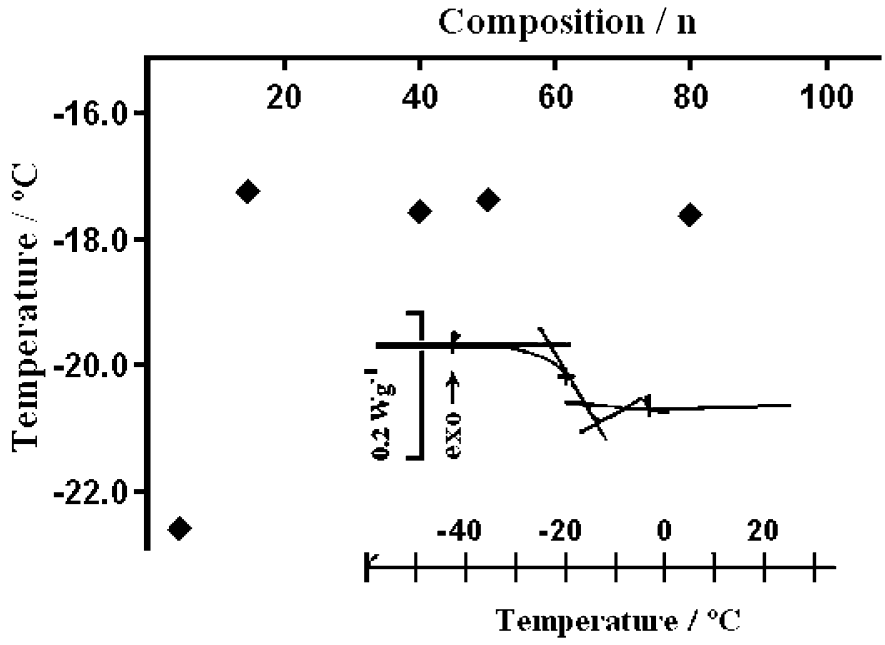

Fig. 1. Variation of glass transition temperature $(\mathrm{Tg})$ with electrolyte composition. Inset shows behavior of $n=5$ electrolyte composition.

electrolyte system the value of Tg was found to be effectively independent of $n$ at low salt content (Fig. 1), similar to the behavior of electrolytes of the lithium trifluoromethanesulphonyl imide, (TMC) $)_{n}$ LiTFSI, system [22]. This latter salt continues to be considered one of the most promising guest species for SPEs, precisely because of its capability to reduce the $\mathrm{Tg}$ of host polymers. In contrast to $\mathrm{p}$ (TMC)-based systems containing lithium perchlorate or lithium triflate, both the lithium trifluoromethanesulphonyl imide and lithium hexafluoroantimonate doped electrolytes show a marked plasticizing effect at high salt content (see inset of Fig. 1). While the variation of the Tgs of electrolytes based on lithium perchlorate and lithium triflate passes through a minimum and then rises at high salt content, the Tg of electrolytes containing both lithium trifluoromethanesulphonyl imide and lithium hexafluoroantimonate continue to decrease with increasing salt content. At compositions of $n$ less than 5, however, neither of these systems have adequate mechanical properties to satisfy the separator functions of a dual electrolyte/separator cell component.

The onset temperature of thermal degradation of electrolyte samples was observed to decrease with an increase in the salt content of electrolytes. In this respect the lithium hexafluoroantimonate-based electrolyte was found to show improved thermal stability relative to electrolytes containing both lithium triflate and lithium perchlorate with similar compositions, as demonstrated by the inclusion of Fig. 2. Lithium perchlorate-based electrolytes suffer exothermic degradation at moderate temperatures while the lithium hexafluoroantimonate, lithium trifluoromethanesulphonyl imide and lithium triflatebased systems degrade endothermally. In commercial devices, such as primary or secondary cells, this aspect of the electrolyte thermal performance is clearly of critical importance, particularly in relation to the practical consequences of severe cell abuse where overheating may be expected.

\subsection{Ionic conductivity of electrolytes}

The conductivity behavior of electrolytes with composition of $n$ between 5 and 100 is reported in Figs. 3 and 4. From the 
data presented in Fig. 3(a) it is immediately apparent that the conductivity is almost independent of composition in the range of $n$ between about 10 and 5. The variation of conductivity with salt may be more clearly seen in the conductivity isotherms of Fig. 4. All the electrolytes based on the p(TMC) host matrix show an increase of total ionic conductivity as the salt content is increased (or $n$ is reduced) and in this respect the lithium hexafluoroantimonate system behaves in a manner consistent with previously characterized systems. This variation of conductivity is explained in terms of an increase in the number of charge carriers available for ionic transport. While in most electrolyte systems the conductivity passes through a readilyidentified maximum and then decreases at higher salt content, in the lithium hexafluoroantimonate electrolyte system this effect is not observed. In this respect this system demonstrates a behavior similar to that of (TMC) ${ }_{n}$ LiTFSI. Once again, this

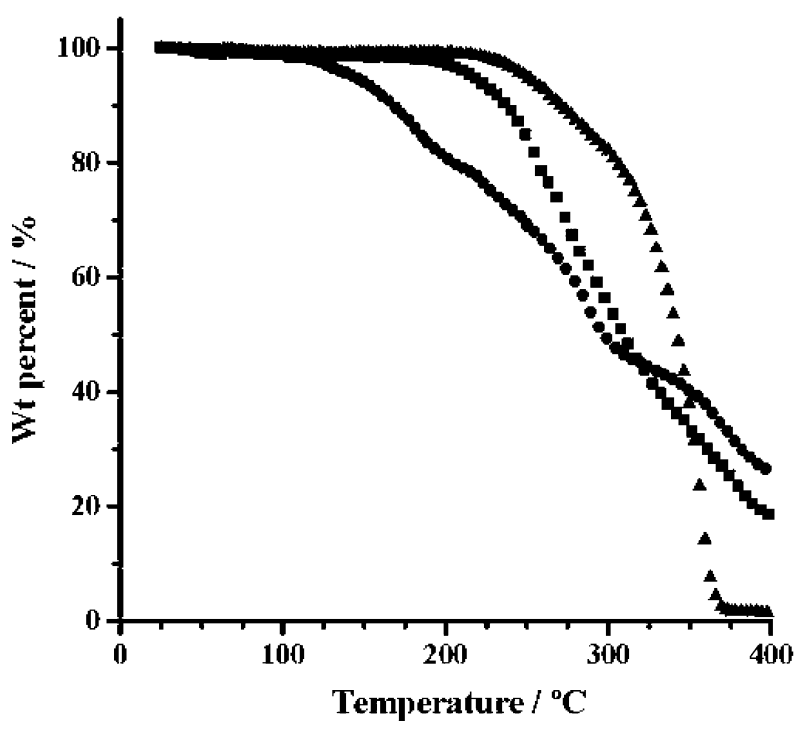

Fig. 2. Thermal decomposition of selected electrolyte compositions (TMC) $n^{-}$ $\mathrm{LiSbF}_{6}$ where $n=5 \bullet, 30 \boldsymbol{\square}$ and $100 \boldsymbol{\Delta}$. observation is consistent with the suggestion that the guest salt exercises a strongly plasticizing effect on the host polymer. In general at high salt content an increase in ion association is observed in polymer hosts with relatively low dielectric constants. Naturally this tendency has consequences in terms of ion mobility and total conductivities tend to decrease. The absence of this effect in the present system may be explained in terms of improved dissociation in this particular polymer/salt combination, however this proposal requires verification by future spectroscopic characterisation. From Fig. 4 we conclude that from the point-of-view of electrolyte conductivity, no further advantage results from the presence of salt compositions greater than about $n=12$. In view of the decrease of thermal and mechanical stability that arises as a consequence of higher salt content, in this system the thermal stability may effectively dictate the optimum electrolyte composition.

\subsection{Electrochemical stability}

The electrochemical stability of the lithium hexafluoroantimonate electrolyte system was determined by microelectrode cyclic voltammetry over the potential range 0 to $6 \mathrm{~V}$. The potential limit for the electrolyte system was determined as the potential at which a rapid rise in current was observed and where the current continued to increase as the potential was swept in the same direction. On the cathode sweep several low current peaks were observed and attributed to the reduction of decomposition products that were formed at the anodic limit. This attribution of peaks was based on a series of experiments in which the anodic limit was successively reduced and the effect on the voltammogram observed. The overall stability of the electrolytes is good with no electrochemical oxidation occurring at potentials less than $5 \mathrm{~V}$. This result is in accordance with expectations that arise from studies of alkyl carbonate-based Kynar gel electrolytes [25] or liquid electrolytes containing asymmetric alkyl carbonates [26,27] and confirm the applicability of this electrolyte composition in practical primary and secondary cells which typically operate within range from 3 to 4 volts.
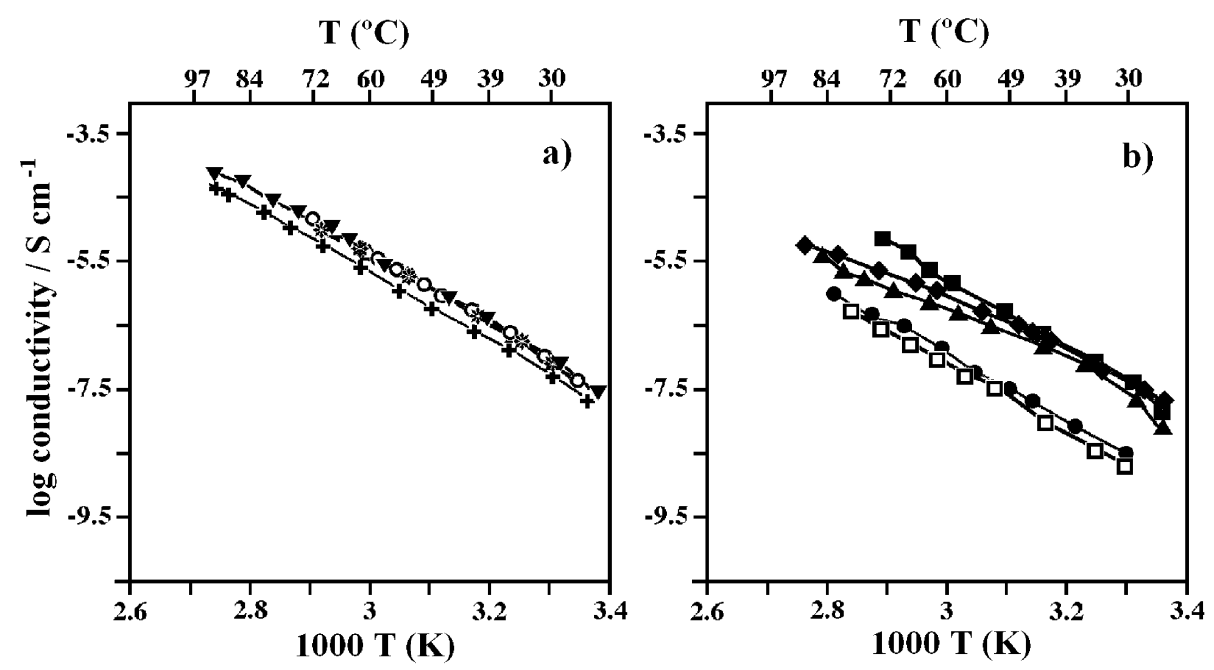

Fig. 3. Variation of ionic conductivity with $1 / T$ for selected electrolyte compositions $(\mathrm{TMC})_{n} \operatorname{LiSbF}_{6}(n=5 \bigcirc, 8 *, 12 \boldsymbol{\nabla}, 15 \boldsymbol{+}, 30 \boldsymbol{\square}, 40 \bullet, 50 \boldsymbol{\Delta}, 80 \bullet$ and $100 \square$ ). 


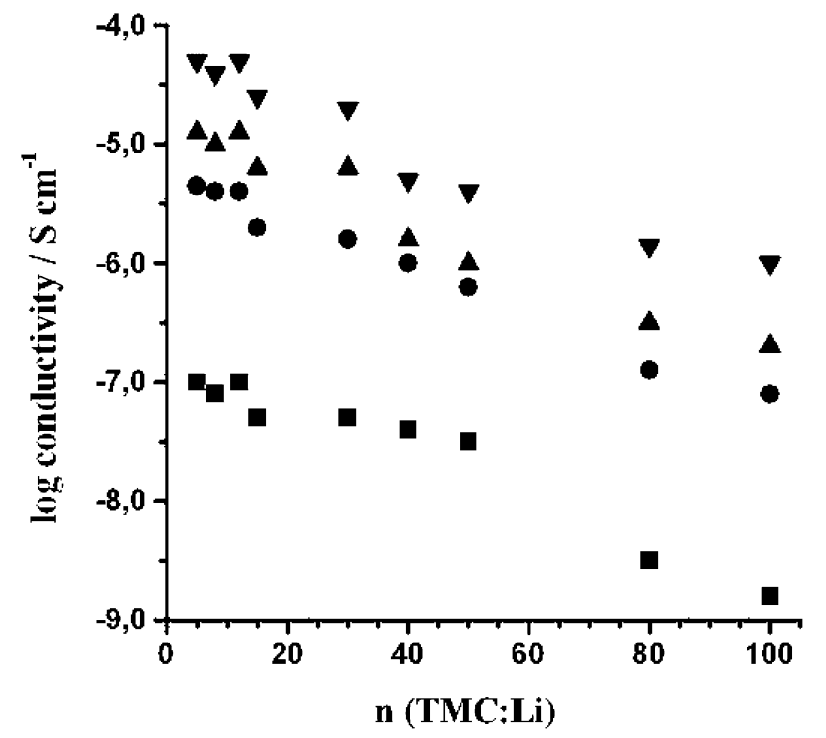

Fig. 4. Conductivity isotherms for the $(\mathrm{TMC})_{n} \mathrm{LiSbF}_{6}$ system $\left(30^{\circ} \mathrm{C}\right.$ $60^{\circ} \mathrm{C} \bullet, 70^{\circ} \mathrm{C} \boldsymbol{\Delta}$ and $85^{\circ} \mathrm{C} \boldsymbol{\nabla}$ ).

\section{Conclusions}

The electrolyte system based on $\mathrm{p}$ (TMC) doped with lithium hexafluoroantimonate is a promising addition to the existing series of electrolytes using this amorphous host and which should be subjected to evaluation in prototype cells. Over the composition range of $n$ between 10 and 15, the electrochemical stability, mechanical and thermal properties are appropriate for dual-function electrolyte separator components. In particular, the thermal degradation of these electrolyte components occurs with a controlled endothermic process that suggests that thermal safety requirements will be readily satisfied. In spite of these encouraging features, it must be acknowledged that the level of room temperature conductivity in these samples is still below the threshold required for commercial exploitation in practical devices. Both the conductivity and thermal behavior observed confirm that this salt exercises a plasticizing effect on the $\mathrm{p}$ (TMC) host polymer and the conductivities reported for electrolytes in the range of $n$ between 10 and 15 motivate further development of this system. Electrochemical stability studies are consistent with previous results obtained with other members of this electrolyte series [28] and indicate that appropriate performance may be expected.

\section{Acknowledgements}

The authors are pleased to acknowledge the support provided by the University of Minho and the Fundação para a Ciência e Tecnologia (contracts POCI/QUI/59856/2004 and $\mathrm{SFRH} / \mathrm{BD} / 22707 / 2005$ ) for laboratory facilities.

\section{References}

[1] D.E. Fenton, J.M. Parker, P.V. Wright, Polymer 14 (1973) 589.

[2] J.R. MacCallum, C.A. Vincent, Polymer Electrolyte Reviews, vol. 1, Elsevier, London, 1987;

J.R. MacCallum, C.A. Vincent, Polymer Electrolyte Reviews, vol. 2, Elsevier, London, 1989.

[3] F.M. Gray (Ed.), Solid Polymer Electrolytes: Fundamentals and Technological Applications, VCH Publishers, New York, 1991.

[4] B. Scrosati, Applications of Electroactive Polymers, Chapman and Hall, London, 1993.

[5] R.G. Linford (Ed.), Electrochemical Science and Technology of Polymers, vol. 1, Elsevier, Amsterdam, 1987;

R.G. Linford (Ed.), Electrochemical Science and Technology of Polymers, vol. 2, Elsevier, Amsterdam, 1991.

[6] F.M. Gray, Polymer Electrolytes, RSC Materials Monographs, Royal Society of Chemistry, London, 1997.

[7] J.R. MacCallum, A.S. Tomlin, C.A. Vincent, Europ. Polymer. J. 22 (1986) 787.

[8] D. Benrabah, J.Y. Sanchez, M. Armand, Electrochim. Acta 37 (1992) 1737.

[9] C. Berthier, W. Gorecki, M. Minier, M.B. Armand, J.M. Chabagno, P. Rigaud, Solid State Ionics 11 (1983) 91.

[10] M. Watanabe, K. Nagaoka, M. Kanba, I. Shinohara, Polymer 14 (1982) 877.

[11] S.M.G. Correia, V. de Zea Bermudez, M.M. Silva, S. Barros, R. Ferreira, A. Sá, L.D. Carlos, A.P. Almeida, M.J. Smith, Electrochim. Acta 47 (2002) 2421.

[12] B. Oh, Y. Hyung, D.R. Vissers, K. Amine, Electrochim. Acta 48 (2003) 2215.

[13] D.J.H. Ballard, P. Cheshire, T.S. Mann, J.E. Preworski, Macromolecules 23 (1990) 1256.

[14] F. Croce, R. Curini, M. Martinelli, L. Persi, F. Ronci, B. Scrosati, R. Caminit, J. Phys. Chem. B 103 (1999) 10632.

[15] M.S. Michael, M.M.E. Jacob, S.R.S. Prabaharan, S. Radhakrishna, Solid State Ionics 98 (1997) 167.

[16] M. Alamgir, K.M. Abraham, in: G. Pistoia (Ed.), Lithium Batteries, Elsevier, Amsterdam, 1994 (Chapter 3).

[17] J.M.G. Cowie, G.H. Spence, Solid State Ionics 109 (1998) 139.

[18] T. Osaka, T. Momma, H. Ito, B. Scrosati, J. Power Sources 68 (1997) 392.

[19] Y. Aihara, M. Kodama, K. Nakahara, H. Okise, K. Murata, J. Power Sources 65 (1997) 143.

[20] M.J. Smith, M.M. Silva, S. Cerqueira, J.R. MacCallum, Solid State Ionics 140 (2001) 345 .

[21] M.J. Smith, M.M. Silva, S.C. Barros, J.R. MacCallum, J. Power Sources 111 (2002) 52-57.

[22] J.R. MacCallum, M.M. Silva, S.C. Barros, M.J. Smith, E. Fernandes, in: G. Nazri, R. Koetz, B. Scrosati, P.A. Moro, E.S. Takeuchi (Eds.), Advanced Batteries and Supercapacitors, The Electrochemical Society Proceedings Series PV2001-21, 2003, p. 476.

[23] M.M. Silva, S.C. Barros, M.J. Smith, J.R. MacCallum, Electrochim. Acta 49 (2004) 1887-1891.

[24] M.J. Smith, C. Silva, Portugaliae Electrochim. Acta 9 (1991) 225.

[25] L. Christie, A.M. Christie, C.A. Vincent, J. Power Sources 81-82 (1999) 378.

[26] G.Y. Gu, S. Bouvier, C. Wu, R. Laura, M. Rzeznik, K.M. Abraham, Electrochim. Acta 45 (2000) 3127.

[27] I. Geoffroy, A. Chagnes, B. Carré, D. Lemordant, P. Biensan, S. Herreyre, J. Power Sources 112 (2002) 191.

[28] D.N. Januário, M. Sc. Thesis, University of Minho, Braga (2004). 